\title{
VALORES Y VIDA COTIDIANA
}

\author{
Emilio Martínez Navarro \\ Universidad de Murcia
}

\begin{abstract}
RESUMEN. Aprender a valorar es un proceso largo y complejo en el que intervienen múltiples sujetos (padres, amigos, profesorado) y múltiples disciplinas (ciencias, artes, humanidades). Pero el éxito del proceso está condicionado por la presencia o ausencia de una actitud básica de búsqueda de la verdad que ha de ser equidistante de dos extremos: del dogmatismo y del escepticismo. Para fomentar una actitud reflexiva y abierta es preciso considerar el aula y los demás espacios educativos como diversas comunidades de investigación, esto es, foros de diálogo, ayuda mutua y búsqueda en común de todo lo que merece ser valorado.
\end{abstract}

ABSTRACT. Learning to value is a long and complex process. Several persons (parents, friends, teachers) and many disciplines (science, art, humanities) take part in it. But the success of this process is conditioned by the presence or absence of a basic attitude: the search of the truth as opposite to dogmatism and skepticism. To advance an open and reflexive attitude is essential conceiving the classroom and other educating places as several communities of inquiry, i.e., circles of dialog, reciprocal help and shared research about all what deserves to be valued.

\section{1. ¿Qué es valorar?}

En la vida cotidiana todos hacemos continuamente valoraciones. Decimos que tal conducta ha sido correcta o incorrecta, que tal situación es justa o injusta, que tal película es estupenda o -por el contrario- decimos que es "un rollazo". También juzgamos a las personas diciendo que tal vecino es simpático, o que es "un pelma". Y a veces juzgamos a colectivos enteros diciendo, por ejemplo, que los profesores son pedantes, o que los médicos son altaneros, o que los maños son tozudos. Hacer valoraciones es algo tan habitual y constante que no se puede imaginar la vida humana sin esa actividad. Podemos afirmar entonces, para empezar esta reflexión, que hay un hecho evidente e indudable, y es que los seres humanos hacemos valoraciones casi con la misma frecuencia que respiramos, y lo mismo que no se puede vivir sin respirar, no se concibe que una persona normal pueda vivir sin valorar.

Ahora bien, inmediatamente observamos que hay distintos tipos de valoraciones y que presentan una doble polaridad -positiva y negativa- ${ }^{\text {: }}$

1. Esta clasificación está inspirada en la de José Ortega y Gasset, "Introducción a una estimativa. ¿Qué son los valores?" en Obras completas, Madrid, Revista de Occidente, vol. VI, 1973, pp. 315-335. 
1) Sensibles -placentero/doloroso, alegre/triste, agradable/desagradable, etc.-

2) Utilitarias -eficaz/ineficaz, exitoso/fracasado, útil/inútil, capaz/incapaz, etc.-

3) Estéticas -bonito/feo, elegante/desaliñado, armonioso/caótico, etc.-;

4) Económicas -caro/barato, con calidad/sin ella, rentable/ruinoso, etc.-;

5) Vitales -sano/perjudicial, fuerte/débil, ágil/torpe, nutritivo/venenoso, etc.-;

6) Intelectuales -evidente/dudoso, verdadero/falso, lógico/absurdo, riguroso/confuso, etc.-;

7) Morales -bondadoso/malvado, justo/injusto, honrado/corrupto, leal/desleal, etc.-;

8) Religiosas -santo/diabólico, sagrado/profano, meritorio/pecaminoso, etc.-

La existencia de estas diferentes clases de valoraciones nos conduce a una cuestión central: ¿Es posible acertar en nuestras valoraciones cotidianas? ¿Cómo podemos mejorar nuestros juicios sobre las situaciones y las personas?

Para responder a esta pregunta es preciso percatarse, en primer lugar, de que esa variedad de tipos de valoraciones nos indica que la realidad cotidiana es maravillosamente compleja: por una parte, porque una misma situación se presta a ser valorada desde perspectivas distintas conforme a esos distintos tipos generales de valoración; pero además, como vamos a ver a continuación, dentro de cada tipo de valoraciones nos vamos a encontrar con un pluralismo de concepciones dispares acerca de los criterios de valoración correcta. Pongamos un ejemplo: una persona está presenciando un partido de fútbol y realiza diferentes juicios valorativos simultáneos, correspondientes a las clases que hemos distinguido anteriormente, de modo que afirma -pongamos por caso- 1) "que es un espectáculo agradable", 2) "que el equipo local está jugando con mayor eficacia que el visitante", 3) "que, en cambio, el equipo visitante está realizando las jugadas más bellas", 4) "que el partido debe haber sido un éxito económico", 5) "que el apoyo de la afición en las gradas está dando fuerzas al equipo local", 6) "que el árbitro no está siendo muy acertado porque no ha visto algunas infracciones evidentes", 7) "que el equipo visitante está dando ejemplo de juego limpio, mientras que algunos jugadores del equipo local son decididamente unos delincuentes" y por último, 8) "valora positivamente que algunos jugadores se hayan santiguado al saltar al terreno de juego". Para llegar a emitir estos ocho enunciados la persona en cuestión ha hecho uso de su capacidad de juicio, aplicando sus criterios particulares a los datos que percibe en la realidad que tiene delante y manejando distintos supuestos que considera correctos. Por ejemplo, para decir que el partido debe haber sido un éxito económico, seguramente ha utilizado el criterio de ocupación de las gradas: si las percibe llenas, infiere que la recaudación habrá sido grande, mientras que si las percibe vacías, infiere que habrá sido pequeña; pero al uso de este criterio y a la percepción que considera válida está añadiendo un supuesto que normalmente es correcto, aunque no siempre ha de serlo: el supuesto de que los ocupantes de las gradas han pagado para entrar al estadio.

Así pues, la complejidad de la realidad es de por sí muy grande con sólo tener en cuenta los diferentes ámbitos de valor que existen, pero la cuestión se complica bastante más cuando nos percatamos de que puede haber distintos criterios para juzgar las situaciones dentro de cada uno de esos ámbitos distintos. Por ejemplo, supongamos que esta persona estaba dirigiendo estos comentarios a su acompañante, pero 
éste no está de acuerdo en algunos de ellos, mientras que sí lo está en otros; no está de acuerdo -pongamos por caso- en que el juego del equipo visitante sea más bello que el del equipo local (3'), ni cree que el apoyo de la afición tenga mucho que ver con las fuerzas del equipo local (5'), ni comparte la opinión de que el árbitro esté desacertado $\left(6^{\prime}\right)$, ni está de acuerdo con que los jugadores descalificados moralmente por su interlocutor estén jugando tan sucio como él dice $\left(7^{\prime}\right)$, ni tampoco aprecia como positivo el hecho de que algunos jugadores se hayan santiguado ( $\left.8^{\prime}\right)$. En cambio, sí está de acuerdo con él en que se trata de un espectáculo agradable (1), en el que el equipo local lleva la voz cantante (2) y en que seguramente el partido ha reportado sustanciosos beneficios económicos (4). El desacuerdo en aquellas cinco áreas de valor indica que esas dos personas, o bien (a) manejan criterios distintos al juzgar en ellas, o bien (b) perciben los hechos de distinta manera -esto puede ser debido a diferencias en el grado de atención y otros factores psicológicos, pero sin duda influyen aquí decisivamente los intereses personales que todos tenemos-, o bien (c) manejan distintos supuestos implícitos que el interlocutor ignora, o bien (d) están en desacuerdo por alguna combinación de todas o de algunas de las razones (a), (b) y (c). Por otra parte, el acuerdo en las otras tres áreas de valor no implica necesariamente que ambas personas llegaron a los mismos juicios desde idénticos criterios y manejando los mismos supuestos, sino que es perfectamente posible que alcanzaran las mismas conclusiones a partir de distintas premisas.

De este modo, a la hora de valorar cualquier situación, nos encontramos con que hay al menos ocho perspectivas distintas, pero complementarias, cada una de las cuales admite a su vez una cierta variedad de juicios diferentes -a menudo contrapuestossegún sean las percepciones, los criterios y los supuestos que maneja la persona que emite el juicio.

Por si fuera poca la complicación que va tomando la acción de valorar, supongamos ahora que una tercera persona solicita a las dos anteriores un juicio global con respecto al partido de fútbol de nuestro ejemplo, y que la primera dice: "un partido muy bueno", mientras que la segunda opina que se trata más bien de "un partido mediocre". Para llegar a este juicio global, supongamos que la primera persona ha sopesado todos los aspectos que antes hemos detallado y que, conforme a su particular escala de prioridades ha llegado a la conclusión de que está viendo "un partido muy bueno", mientras que la segunda persona, haciendo uso a su vez de otra escala de prioridades particular, con la cual ha sopesado sus juicios anteriores, llega por su parte a creer que está presenciando "un partido mediocre". Esta situación ilustra lo que pretendo enfatizar en este momento: que cada persona maneja, además de los criterios, percepciones y supuestos correspondientes a cada área de valor, una particular escala de valores que se refiere al modo en que concede prioridad a unas u otras áreas de valor frente a las otras. Así por ejemplo, la persona que concede prioridad a las consideraciones económicas -pongamos por caso- frente a las morales y estéticas, probablemente llegará a juicios globales muy distintos a los de la persona que valora más lo moral y estético que lo económico.

Volvamos a la cuestión que teníamos planteada al comienzo: ¿Cómo podemos saber si nuestras valoraciones cotidianas son correctas? Creo que, a la vista de la complejidad propia de las acciones valorativas, la única respuesta que puede darse a esta 
pregunta es la siguiente: hay que trabajar en dos frentes simultáneamente, por una parte mejorando nuestros criterios, percepciones y supuestos dentro de cada una de las áreas de valor mediante una investigación continua, y por otra parte mejorando también nuestra particular escala de prioridades en cuanto a las áreas de valor, siempre a través de la investigación continua ${ }^{2}$.

En resumen, hemos visto en este apartado que 1) valorar es realizar unos juicios -los juicios valorativos-, 2) que tales juicios pueden ser de distintos tipos -conforme a lo que hemos Ilamado "las áreas de valor"-, 3) que dentro de cada área de valor cada cual valora teniendo en cuenta los criterios, las percepciones y los supuestos que estén a su alcance, 4) que en cada juicio valorativo global hacemos uso de nuestra particular "escala de valores" con la cual establecemos prioridades entre las áreas de valor, y 5) que, tanto nuestras valoraciones parciales -dentro de cada área de valor- como las globales, podemos mejorarlas a través de una continua actividad de investigación. En los apartados siguientes trataremos de aclarar en qué consiste dicha investigación y cómo podemos promoverla en nuestras aulas y en nuestras vidas con alguna probabilidad de éxito.

\section{2. ¿Cómo podemos mejorar nuestras valoraciones cotidianas?}

Algunas personas tienden a decir que en cuestión de valores todo es subjetivo, que las valoraciones de cada cual son igualmente acertadas, que en el campo de los valores no existe la objetividad ni puede llegar a existir. Estas personas sostienen que hay una radical separación entre hechos y valoraciones ${ }^{3}$ : sobre hechos sí creen que existe objetividad, puesto que hay ciertos procedimientos para saber cuáles son realmente los hechos en un momento dado; en cambio, según estas personas, no puede haber objetividad en las valoraciones, dado que en ellas intervienen muchos rasgos particulares -en especial, los intereses- de quienes valoran.

Sin embargo, hay algo que falla en esa mentalidad que atribuye toda la objetividad a los juicios fácticos y ninguna objetividad a los juicios valorativos: ¿Acaso la objetividad de los hechos no se ha de establecer comunitariamente, intersubjetivamente, a través de la deliberación entre quienes dicen conocerlos? De modo similar, la objetividad de las valoraciones se puede establecer en muchos casos a través de un proceso deliberativo en el que intervienen quienes tratan de saber en qué medida es acertada su valoración inicial sobre algo o sobre alguien.

2. Naturalmente, algunos dirán que esta empresa está de antemano condenada al fracaso, porque piensan que no existe la correcta escala de valores, ni tampoco los criterios acertados en el seno de las áreas de valor, sino que más bien lo que hay es lo que Max Weber Ilamaba "politeísmo axiológi-

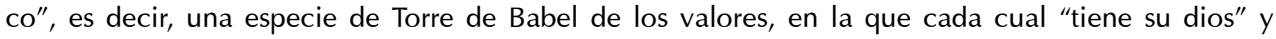
supuestamente no existe modo alguno de alcanzar un consenso en torno a cuestiones de valor. Sin embargo, existen buenas razones para creer que Max Weber estaba parcialmente en lo cierto, pero también, parcialmente equivocado. Para una exposición clara de estas cuestiones, véase Cortina, A., La ética de la sociedad civil, Madrid, Anaya, 1994.

3. En efecto, ésa es la posición de la mentalidad cientificista que ha tenido su expresión filosófica más clara en los autores pertenecientes al Neopositivismo Lógico de la primera mitad del siglo XX (Russell, Círculo de Viena, etc.). También han sostenido la radical dicotomía entre hechos y valores los partidarios del Emotivismo ético en la Filosofía Analítica (A.J. Ayer, Ch. L. Stevenson) y los existencialistas como Sartre. 
En el caso de los hechos, todos necesitamos contrastar la información recibida sobre un presunto hecho con el mayor número posible de otras personas y también a través de nuestras propias capacidades perceptivas e intelectuales (capacidades que hemos podido desarrollar anteriormente con la ayuda de la comunidad que nos ha educado). Y en el caso de las valoraciones también sentimos la misma necesidad de contrastar con otros las nuestras y de revisarlas en nuestro propio pensamiento hasta alcanzar un punto de equilibrio en el que sentimos que la propia valoración no es fruto del capricho, sino un juicio dotado de una base objetiva, puesto que lo hemos sometido a una revisión intersubjetiva y ha conseguido mantenerse en pie $^{4}$.

Naturalmente, cualquier juicio de hecho y cualquier juicio valorativo son susceptibles de una ulterior revisión, puesto que casi nunca está garantizada la objetividad plena, y pueden aparecer nuevos datos o nuevas reflexiones que nos impulsen a reconsiderar lo que anteriormente habíamos considerado acertado. Pero lo que interesa subrayar es que la objetividad es siempre intersubjetividad, que necesitamos contrastar con otros sujetos las informaciones y las valoraciones para llegar a considerarlas como objetivas y que incluso cuando nos valemos de nuestros propios recursos personales para emitir juicios fácticos y valorativos, hay toda una comunidad que nos ayudó previamente a desarrollar tales recursos personales mediante orientaciones que hemos interiorizado acerca de lo que se puede considerar objetivo y lo que no.

De este modo vamos llegando a una respuesta preliminar a la pregunta que encabeza este apartado: podemos mejorar nuestras valoraciones cotidianas revisándolas con otros y también en la intimidad de nuestro pensamiento, haciendo uso en todo caso del proceso racional que Ilamamos deliberación. Tanto si se trata de conocimientos empíricos, como de valoraciones de cualquier área de valor, nuestros juicios son mejorables contrastándolos con otros juicios que puedan aportar personas reales o imaginarias ${ }^{5}$.

Ahora bien, creer, como creemos aquí, que es posible mejorar nuestros juicios valorativos de modo semejante a como es posible progresar en nuestro conocimiento de los hechos, Ileva consigo un distanciamiento de dos extremos: del dogmatismo y del escepticismo. Las personas que sostienen sus juicios desde actitudes dogmáticas no creen que sea necesaria la deliberación: se aferran fanáticamente a unas creencias que consideran como verdades absolutas y no buscan ni ofrecen a los demás argu-

4. En este punto conviene consultar las reflexiones de M. Lipman acerca de la mejora del pensamiento en su obra Pensamiento complejo y educación, trad. e introd. de Virginia Ferrer, Madrid, De la Torre, 1997.

5. M. Walzer ha desarrollado la idea -por otra parte nada nueva- de que en el interior de nuestro pensamiento individual existe una pluralidad de voces distintas que se ha ido formando al hilo del trato con los demás, de las lecturas realizadas, etc., y que, por tanto, toda persona es multifacética, aunque siempre hay un ego que sintetiza de modo más o menos coherente la multiplicidad interna (cfr. Walzer, Michael: "El individuo dividido", cap. 5 de Moralidad en el ámbito local e internacional, Madrid, Alianza, 1996). Sócrates ya solía decir que oía en su interior la voz de su "daimon". Platón creía que en el seno del alma pugnan entre sí las voces de la razón con las de los sentimientos y las de los deseos, constituyéndose de este modo en un claro precedente de las teorías de Freud. Hölderlin lo expresó poéticamente diciendo que "somos un diálogo" y G.H. Mead mostró las bases sociales de la personalidad individual en su obra de 1934 Espíritu, persona y sociedad (Barcelona, Paidós, 1985). 
mentos comprensibles que avalen tales creencias. A lo sumo profieren amenazas y descalificaciones globales a las opiniones ajenas, sin detenerse a explicar racionalmente las propias. Por el otro extremo, quienes sostienen actitudes escépticas tampoco son dados a la práctica de la deliberación, puesto que están convencidos de antemano de que todas las opiniones poseen el mismo valor: todo el mundo tiene razón, asi que ¿para qué vamos a tomarnos la molestia de argumentar en un diálogo, tanto si es con otros como si es con uno mismo?

Sin embargo, si lo pensamos despacio, tanto el dogmatismo como el escepticismo son actitudes que no casan con la realidad cotidiana, porque antes o después conducen a quienes dicen sostenerlas a un callejón sin salida. El fanatismo dogmático ha dado a lo largo de la historia -y desgraciadamente sigue dando en la actualidad- sobradas muestras de cuánta crueldad y cuánto sufrimiento absurdo es capaz de generar en el mundo. Por su parte, el escepticismo es una posición que genera una indiferencia cómplice ante esa crueldad y esos sufrimientos que la humanidad padece. Si en la historia hubiesen predominado esas dos actitudes, no habría nacido la ciencia, ni se hubiesen inventado las técnicas ni los artefactos que hoy hacen nuestra vida más segura y próspera, ni tampoco se hubiesen puesto en marcha las instituciones sociales como la democracia o los derechos humanos.

La actitud que está en la base de todas esas realidades valiosas que hoy forman parte de nuestra vida es la actitud que podemos Ilamar "razonabilidad": ser razonable equivale entonces a sostener las propias creencias con convicción y con argumentos (frente al escepticismo), pero al mismo tiempo con una disposición permanente a dejarse convencer por argumentos mejores, si éstos se le presentan, reconociendo que uno no está en posesión de la verdad absoluta, sino que muy bien podría estar equivocado (frente al dogmatismo). En otras palabras, ser razonable es reconocer sensatamente que uno está a medio camino entre la ignorancia absoluta y la plena posesión de esa verdad que se busca, y que los demás están aproximadamente en la misma situación; por lo tanto, la persona razonable se apresta a decir a los demás qué es lo que cree y por qué lo cree, ofreciendo las pruebas y argumentos de que dispone, pero al mismo tiempo se mantiene en disposición de valorar con equidad los argumentos de los demás y a reconocer sus propios errores cuando los detecte ${ }^{6}$.

Este planteamiento nos lleva a darnos cuenta de que el primer paso para intentar siquiera una pequeña mejora en nuestras valoraciones cotidianas es tomar conciencia de lo insostenibles que son las actitudes dogmáticas y escépticas, y comprometerse claramente con la idea de que tal mejora de nuestros juicios es posible y deseable. A continuación, este compromiso nos impulsa a mirar nuestras convicciones actuales como valiosas, pero provisionales: como quien tiene un pequeño tesoro y sueña con aumentarlo pero sabe que sólo lo puede conseguir si lo arriesga invirtiendo en diversos negocios. Esos negocios son, en este caso, el estudio reflexivo personal y los debates, las discusiones y las meditaciones, las controversias con otros y con uno mismo

6. Véase mi trabajo "La filosofía en el aula: por una democracia integral" en Paideía, n1 13-14 (1991), pp. 137-145, en el que propongo argumentos tomados de la filosofía contemporánea para apoyar la necesidad de promover la reflexión y el diálogo en todas las instituciones sociales, particularmente en las aulas. 
en una búsqueda interminable de nuevas verdades que puedan sustituir a las de ahora por sus propios méritos (es decir, no por los vaivenes de la moda, sino por la evidencia de los mejores argumentos). Hace falta una buena dosis de ánimo y de espíritu deportivo ${ }^{7}$, porque no siempre está uno dispuesto a reconocer que una opinión de otra persona es realmente más acertada que la que uno mismo sostenía hasta ahora. Sin embargo, un buen deportista sabe que una derrota es una excelente ocasión para aprender de los propios errores y de los aciertos del ganador. Al final, lo que importa es jugar con la moral alta y con juego limpio, porque las chapuzas -a medio y largo plazo- no conducen más que a la desmoralización y al ridículo.

Hemos de ser conscientes de que en nuestra vida cotidiana cedemos con mucha facilidad a las tendencias chapuceras; nos resulta más cómoda la rutina, el prejuicio, la desidia, que el esfuerzo innovador de búsqueda personal y comunitaria de nuevas perspectivas más acertadas. Siempre nos acecha el fantasma de no ser aceptados por nuestro grupo, el miedo a resultar incómodos para los que tienen algún poder para hacernos daño. $\mathrm{Y}$ cuando llevamos mucho tiempo tratando de ser críticos con el entorno y con nosotros mismos, suele aparecer el cansancio y la soledad del corredor de fondo. Sin embargo, todos estos riesgos son mucho menores si nos sentimos formando parte de una comunidad de investigación. Porque, en tanto que comunidad, nos proporciona el apoyo y el estímulo que todos necesitamos, siendo como somos seres vulnerables y con limitaciones, y en tanto que investigadora nos asegura un clima de razonabilidad, de indagación por métodos lógicos y equitativos, un clima de cooperación en la que se respetan unas libertades personales. Porque una comunidad de investigación es todo lo contrario que una secta: mientras que ésta última es un grupo cerrado, jerárquico, dogmático y enemigo de la crítica interna, las comunidades de investigación son abiertas, igualitarias, deliberativas y estimuladoras de la autocrítica ${ }^{8}$.

Todos podemos impulsar comunidades de investigación en nuestro entorno cotidiano: en la propia familia y en la escuela, en la peña de amigos y en el grupo deportivo, en el grupo religioso y en el sindicato, en la asociación de vecinos y en el partido político, etc. Las instituciones que asumen los presupuestos y los métodos de una comunidad de investigación son más humanizadoras, más éticas, mejores para las personas y para el entorno natural, que aquellas que los pisotean o los ignoran. Porque en la medida en que se organiza un grupo al modo de las comunidades de investigación, el resultado no puede ser otro que la creación de un clima interno que favorece el respeto mutuo, las libertades básicas, la igualdad, la solidaridad y la actitud de diálogo. En otras palabras: las comunidades de investigación son grupos humanos que se comprometen activamente con los valores que hasta el momento han mos-

7. Véase la caracterización que hace Ortega y Gasset de la moral como síntoma de estar uno "en su propio quicio y en su propia eficacia vital", frente al estar "desmoralizado", en *Por qué he escrito El hombre a la defensiva+, Obras completas, Madrid, Revista de Occidente, IV, p. 72.

8. Sobre las características y procedimientos propios de la comunidad de investigación, véase Sharp, A.M.: “¿Qué es una *comunidad de investigación+?”, trad. de J.C. Lago Bornstein, en Aprender a pensar, n1 2 (1990), pp. 7-18, y también las referencias a la misma contenidas en Lipman, M.: Pensamiento complejo y educación, Madrid, De la Torre, 1997. 
trado ser indispensables para una convivencia justa entre personas que se consideran iguales en dignidad y derechos ${ }^{9}$.

\section{3. ¿Que podemos hacer para que nuestros alumnos y alumnas mejoren sus valoraciones cotidianas?}

La tarea de la Educación en Valores es algo que los educadores y educadoras hemos hecho siempre, que seguimos haciendo y que nunca podremos dejar de hacer. Porque desde el mismo instante en que entramos en contacto con nuestras alumnas y alumnos les estamos mostrando -a través de nuestro comportamiento en el aula y en el Centro- un determinado estilo de vida, una personal actitud ante las cosas y ante las personas, una manera de ver el mundo. Nadie puede pretender -sin engaño- que se limita a realizar una labor de transmisión de los conocimientos que corresponden a su especialidad.

Ciertamente, los chicos y chicas que tenemos en clase ya traen asimilados muchos de los valores que orientan sus vidas. Se han empapado de ellos a través de su familia, de sus vecinos y amigos, de sus maestros anteriores y de otras personas de su entorno cercano, además de las influencias que puedan haber recibido de los programas de televisión y de otros medios de comunicación de masas. A nosotros nos llegan equipados con un bagaje de actitudes positivas y negativas, de virtudes y de vicios, de valores positivos y negativos. Nuestra responsabilidad consiste en ayudarles a madurar un poco más, aportar nuestro propio grano de arena a la construcción de su propia personalidad; nada más, pero nada menos.

Lo que se nos pide desde la Administración Educativa es que hagamos el esfuerzo de explicitar lo más claramente posible el QUÉ, el CÓMO, el CUÁNDO, y el POR QUÉ de esos valores que queremos transmitir a nuestros alumnos y alumnas. Para ello se insiste una y otra vez en las directrices ministeriales en que el profesorado y el resto de la comunidad educativa se ponga de acuerdo en cada Centro sobre dichas cuestiones; al mismo tiempo, las publicaciones oficiales ofrecen pistas y orientaciones para llevar a la práctica el consenso obtenido. Se supone que tal consenso no puede dejar de lado los grandes valores que sustentan la convivencia en las democracias liberales como la nuestra: la libertad, la igualdad, la solidaridad, el respeto mutuo y la actitud de diálogo. Otros muchos valores pueden ser priorizados en algunos Centros concretos, pero será difícil que puedan ignorarse los que acabo de mencionar, puesto que sin ellos no resulta posible una convivencia satisfactoria en las sociedades pluralistas modernas. Sin tomarse en serio estos valores tampoco puede haber en el Centro de Enseñanza un clima verdaderamente educativo.

9. Para una justificación de la necesidad de conceder prioridad a estos valores frente a otros, véase A. Cortina, J. Escámez y E. Pérez-Delgado: Un mundo de valores, Valencia, Generalitat Valenciana, 1996, capítulos 1-3; también mi trabajo "Justicia" en Cortina, A. (Dir.): 10 palabras clave en Ética, Ed. Verbo Divino, Estella, 1994. En una línea similar, pero con mucho más aparato teórico, son recomendables las obras de Brian Barry (Justicia como imparcialidad, Barcelona, Paidós, 1997) y de Teresa de la Garza (Educación y democracia. Aplicación de la teoría de la comunicación a la construcción del conocimiento en el aula, Madrid, Visor, 1995. 
Una vez explicitados en el Proyecto Educativo de Centro (PEC) los valores en los que se quiere educar, el siguiente paso es concretar esas intenciones de modo coherente en el Reglamento de Régimen Interior (RRI) y en los Proyectos Curriculares de Etapa y de Área. Pero lo más importante no son los documentos, naturalmente, sino que éstos reflejen realmente que existe en nosotros un compromiso serio con unos valores sólidamente asumidos y claramente expresados en nuestra práctica cotidiana. Por muchos papeles que redactemos, lo que finalmente cuenta para educar en valores es el clima que logremos crear en el Centro y el ejemplo que nuestros alumnos y alumnas puedan ver en nosotros de aquello que decimos creer. Esta es la razón por la que todos los profesores y profesoras de un Centro -e incluso todo el personal adulto que trabaja en el mismo- tiene como tarea transversal la de educar en valores a los jóvenes que acuden a él. $Y$ digo "tarea transversal" por razones obvias: en primer lugar, porque ante todo se trata de una tarea, de una actividad continuada, y no de un simple "tema". Y en segundo lugar porque concierne a todos y a todas, tengamos la especialidad que tengamos, y por eso se trata de algo "transversal".

Llegados a este punto debería estar claro que la "Educación en Valores" y los Ilamados "Temas Transversales" son cosas distintas, aunque muy relacionadas. La "Educación en Valores" es la Educación sin más: educar es precisamente ayudar a progresar en todas las áreas de valor. La Educación en Valores es esa tarea transversal que debemos cuidar en todas las actividades dentro y fuera de las aulas, con la mirada puesta en que todos los miembros de la comunidad educativa, incluidos los profesores, vayamos progresando en razonabilidad, en espíritu crítico, en creatividad, en una palabra: en excelencia humana. En cambio, los "Temas Transversales" que nos propone el actual sistema educativo son unas enseñanzas que tienen mucho que ver con esa tarea de educar en valores, pero que poseen unos contenidos propios y específicos que pertenecen a distintas áreas o materias. Recordemos que los Temas Transversales en la Educación Primaria y en la E.S.O. son los siguientes: 1) La educación moral y cívica, 2) La educación para la paz, 3) La educación para la salud, 4) La educación para la igualdad de oportunidades entre los sexos, 5) La educación ambiental, 6) La educación sexual, 7) La educación del consumidor y 8) La educación vial.

El primero de estos ocho "temas" es, a mi juicio, el más englobante de todos, puesto que sus contenidos no sólo atraviesan todas las áreas y todas las actividades que se lleven a cabo en un Centro, sino que atraviesan también al resto de los temas transversales. Sin embargo, aunque se podría pensar que "la suma" de los demás temas transversales da como resultado una buena educación moral y cívica, creo que esto no es exactamente así. Lo que quiero decir es que aun en el caso de que una persona asumiera los valores de la paz, la salud, la relación no sexista, el respeto a la naturaleza, la sexualidad sana, el consumo responsable y la recta conducta vial, todavía cabe la posibilidad de que la educación moral y cívica le aporte otros valores importantes que tal vez no estén recogidos en esos otros siete ${ }^{10}$. En resumen, lo que sostenemos aquí es que los temas transversales son una parte de la Educación en Valores, y no toda esa

10. Para una atinada reflexión acerca de la prioridad de los valores morales como objetivos de nuestro trabajo en las aulas, véase A. Cortina, El quehacer ético. Guía para la educación moral, Madrid, Santillana, 1996. 
tarea. Y que hay un tema transversal (La Educación Moral y Cívica) que sin duda es el más amplio de todos, puesto que nos invita a profundizar en los valores morales, pero la "Educación en Valores" es más amplia todavía, puesto que incluye también la atención a otros tipos de valores, como por ejemplo los estéticos, los utilitarios o los religiosos.

En el siguiente cuadro se puede apreciar cómo entendemos aquí la relación entre la Educación en Valores y los Temas Transversales:

\begin{tabular}{|c|c|c|}
\hline \multirow{11}{*}{$\begin{array}{l}\text { EDUCACIÓN } \\
\text { EN } \\
\text { VALORES } \\
\text { (= Educación en } \\
\text { el pleno sentido } \\
\text { de la palabra) }\end{array}$} & \multicolumn{2}{|c|}{ "Clima" educativo del Centro y en cada aula } \\
\hline & \multicolumn{2}{|c|}{ Contenidos actitudinales de cada área } \\
\hline & \multirow{3}{*}{$\begin{array}{l}\text { Temas } \\
\text { transversales }\end{array}$} & Desarrollados en las áreas \\
\hline & & Desarrollados en la tutoría \\
\hline & & Desarrollados en actividades complementarias \\
\hline & \multirow{6}{*}{$\begin{array}{l}\text { Reflexión es- } \\
\text { pecífica sobre } \\
\text { Valores }\end{array}$} & $\begin{array}{l}\text { Morales (justicia, honradez, bondad, lealtad, etc.): } \\
\text { Ética, Ciencias Sociales, Cultura clásica, Educación Física, } \\
\text { Religión, etc. }\end{array}$ \\
\hline & & $\begin{array}{l}\text { Estéticos (belleza, elegancia, creatividad, armonía, etc.): } \\
\text { Música, Plástica, Literatura, Cultura clásica, Ed. Física, etc. }\end{array}$ \\
\hline & & $\begin{array}{l}\text { Religiosos (sentido de lo sagrado, fe, esperanza, etc.): } \\
\text { Religión, Ética, Ciencias Sociales, etc. }\end{array}$ \\
\hline & & $\begin{array}{l}\text { Intelectuales (verdad, rigor, evidencia, etc.): } \\
\text { Matemáticas, Lógica, Ciencias de la Naturaleza, CC. Sociales, } \\
\text { etc. }\end{array}$ \\
\hline & & $\begin{array}{c}\text { Vitales (salud, agilidad, flexibilidad, vitalidad, fortaleza): } \\
\text { Ed. Física, Ciencias de la Naturaleza, etc. }\end{array}$ \\
\hline & & $\begin{array}{c}\text { Utilitarios (calidad, aplicabilidad, utilidad, eficacia, rentabilidad, } \\
\text { etc.): } \\
\text { Lenguaje, Tecnología, Idiomas, Matemáticas, Ciencias de la } \\
\text { Naturaleza, CC. Sociales, etc. }\end{array}$ \\
\hline
\end{tabular}

A la vez que aseguramos lo más posible la integración vivencial de los valores en la organización y en el clima interno del Centro, hemos de integrar al máximo los temas transversales en los diseños curriculares de las distintas áreas. Algunas se prestan muy bien a desarrollar algunos temas transversales: por ejemplo, la Educación Ambiental y la Educación para la Salud encajan perfectamente en el Área de Biología y Geología, la Educación para la Paz encaja muy bien en el Área de Ciencias Sociales, etc. En la medida de lo posible, los contenidos de los temas transversales deberían ser tratados de un modo plenamente coherente e integrado en las áreas mismas. Porque no se trata de añadir contenidos nuevos a los que ya forman parte de las áreas o materias que impartimos, sino de organizar los contenidos propios de cada una de ellas de un modo particular: de un modo que asegure, en lo posible, la asimilación de esos contenidos que hoy en día son fundamentales. Ciertas áreas que de suyo no guardan relación directa con ninguno de los temas transversales -como puede ser el área 
de Matemáticas- pueden ensayar modos imaginativos de integrarlos -como, por ejemplo, a través de los enunciados de los ejercicios. Cada Departamento o especialidad puede incluir en su programación algunos temas transversales sin necesidad de ampliar los contenidos que tiene asignados por ley: basta con enfocar esos mismos contenidos de tal manera que se atienda simultáneamente a los ejes transversales. Para facilitar esta labor podría ser útil la plantilla adjunta: en ella podemos ir reflejando el título o el número de las unidades didácticas en las que se tendrá en cuenta cada uno de los temas y el título o el número de las actividades concretas que tienen que ver con tales temas.

CURSO 199_-199_. MATERIA NIVEL

\begin{tabular}{|l|l|l|}
\hline TEMA TRANSVERSAL & UNIDADES DIDÁCTICAS & ACTIVIDADES \\
\hline Ed. moral y cívica & & \\
\hline Ed. para la paz & & \\
\hline Ed. para la salud & & \\
\hline Ed. no sexista & & \\
\hline Ed. ambiental & & \\
\hline Ed. sexual & & \\
\hline Ed. del consumidor & & \\
\hline Ed. vial & & \\
\hline
\end{tabular}

De este modo es posible que la mayor parte de los temas transversales sean adecuadamente integrados por las distintas áreas, pero conviene que alguien se encargue de comprobar si entre todas las que forman parte del ciclo y de la etapa se están cubriendo todos esos temas. No sería extraño que haya alguno que las áreas no consiguen integrar o que no se atreven a tratar de un modo explícito. El caso más corriente es el de la Educación sexual: a menudo se prefiere tratarla en el ámbito de la tutoría o por medio de conferencias o sesiones específicas a cargo de especialistas. Lo importante es que este tipo de casos sea la excepción, y no la regla.

Por otra parte, no está de más que se aprovechen ciertas ocasiones especiales a lo largo del curso escolar para desarrollar la sensibilidad en torno a los temas transversales. Por ejemplo, se pueden montar actividades interdisciplinares en torno al "Día Mundial del Medio Ambiente", la "Jornada Internacional por la Paz", el "Día de la Mujer Trabajadora", etc. También se pueden aprovechar las fiestas patronales o similares para organizar exposiciones y actividades ambientadas en torno a algún tema vinculado a los transversales. Otro tanto puede decirse de las excursiones, los viajes de estudio y demás. Este modo de abordar los temas transversales no debería sustituir, sino complementar, al que hemos comentado anteriormente como básico y fundamental: la integración -hasta donde sea posible- en los propios contenidos de las áreas. 
Ahora bien, tanto si se trata de la organización global del Centro, como de un aula concreta, y tanto al trabajar los contenidos propios de un área como al desarrollar los contenidos transversales, no deberíamos perder de vista dos elementos fundamentales: el primero es que la meta es ser todos más razonables, dotarnos todos -particularmente los alumnos y alumnas, que son los destinatarios del sistema educativo- de una mayor capacidad de juicio"1. El segundo punto fundamental es que tal cosa no se puede conseguir si no creamos en el aula una comunidad de investigación.

En definitiva, podremos mejorar las valoraciones cotidianas de nuestros alumnos y alumnas si adoptamos lo que Lipman ha llamado "el paradigma reflexivo" en educación, cuyos principios recogemos a continuación ${ }^{12}$ :

1. La educación es el resultado de la participación en una comunidad de indagación guiada por el profesor, entre cuyas metas están el logro de la comprensión y del buen juicio.

2. Se estimula a los estudiantes a pensar sobre el mundo cuando nuestro conocimiento de él se les revela ambiguo, equívoco y misterioso.

3. Las disciplinas en cuyo interior se generan procesos de indagación, pueden yuxtaponerse entre ellas y además no son exhaustivas en relación con su respectiva área de conocimiento, que es problemática.

4. El profesor adopta una posición de falibilidad (aquel que está dispuesto a admitir que se ha equivocado) más que de autoritarismo.

5. Se espera que los estudiantes sean reflexivos y pensantes, progresivamente más razonables y juiciosos.

6. El objetivo principal del proceso educativo no es la adquisición de información, sino la captación de las relaciones que existen entre las materias que son objeto de investigación".

\section{Referencias bibliográficas}

BUXARRAIS, Ma Rosa, y otros: La educación moral en primaria y en secundaria, Edelvives/MEC, Zaragoza y Madrid, 1995.

CORTINA, A.: El quehacer ético. Guía para la educación moral, Madrid, Santillana, 1996.

- La ética de la sociedad civil, Madrid, Anaya, 1994.

- Ética civil y religión, Madrid, PPC, 1995.

CORTINA, A. y MARTíNEZ, E.: Ética, Madrid, Akal, 1996.

11. Véase Lipman, M.: Pensamiento complejo y educación, cit.

12. Ibid., pp. 55-56 (he alterado ligeramente la traducción que aparece en la edición española porque creo que contiene pequeños errores que deberían ser subsanados en futuras reediciones de la obra). 
DE LA GARZA, Ma TERESA, Educación y democracia. Aplicación de la teoría de la comunicación a la construcción del conocimiento en el aula, Madrid, Visor, 1995.

GARCÍA MORIYÓN, Félix, *Reflexión filosófica y enseñanza de los valores+, en Estudios filosóficos № 108 (1989), pp. 287-318.

GRUPO "FILOSOFIA PARA NIÑOS Y NIÑAS", Aprender a pensar en diálogo, Murcia, Centro de Profesores no 1, 1992.

GRUPO XIBECA: Los dilemas morales. Un método para la educación en valores, Valencia, Nau-llibres, 1995.

LIPMAN, M y otros: La filosofía en el aula, Madrid, De la Torre, 1992.

LIPMAN, M.: Pensamiento complejo y educación, Madrid, De la Torre, 1997.

ORTEGA, P./ MÍNGUEZ, R./ GIL, R.: La tolerancia en la escuela, Barcelona, Ariel, 1996.

PÉREZ DELGADO, Esteban, y GARCÍA ROS, Rafael (Comps.): La psicología del desarrollo moral, Madrid, Siglo XXI, 1991.

PÉREZ DELGADO, Esteban, y MESTRE, Ma Victoria: El crecimiento moral, Universitat de Valencia, 1995. 